role of the nucleolus. Most of the recent work has been done on plant cells. Although it is essential that much more attention be given to the nucleoli of animal nuclei, sufficient has been accomplished to show that plant and animal nucleoli are similar in essentials.

Three important discoveries during this century have determined the trend of modern research on the nucleolus. In 1912 were first seen, in Galtonia, chromosomes with satellites to which the nucleolus was connected. In 1926, the discovery in meiosis of Lathyrus of the 'nucleolar body' established a definite connexion between the chromosomes and the nucleolus. This body was a globule within the nucleolus to which the 'continuous spireme' was attached in prophase. With the methods then in use chromatin thread and nucleolar body stained similarly. In 1934, it was found that a 'nucleolar organizer' existed at a fixed point on certain chromosomes of maize. It was not of necessity visible as a separate entity but the nucleolus always arose in telophase at this point.

It is now well established that nucleoli are produced from the chromosomes in the telophase of mitosis. Each nucleus contains at least one pair of nucleolar chromosomes and each of the pair produces a nucleolus. The nucleolar chromosomes are frequently the sex chromosomes. Each of the pair has attached to it, by a very fine thread, a satellite which may be exceedingly small or may be a globular body as wide as the chromosome. The nueleolar organizer is usually at the tip of the chromosome at the point of attachment of the satellite thread; but it may be placed farther back at a secondary constriction. Suitable technique shows the origin of the nucleolus to consist of two minute granules, one on each strand, which stain similarly to the chromosome sheath. They may be formed from the material of this sheath, for it disappears as the granules increase in size. Any two nucleoli which touch because of growth or due to chromosome movement within the nucleus merge together. By the following prophase all are usually fused into a single body to which all the nucleolar chromosomes for some time remain attached. They break away when the nuclear membrane breaks down in late prophase and the nucleolus passes into the cytoplasm and disappears. A previous decrease in size of the nucleolus suggests that it may contribute material to the sheaths of the newly differentiated chromosomes.

The presence of several nucleoli at telophase, all of which fuse into one body before prophase, has been frequently described, but only recently has it been realized that the number of nucleoli is constant within any one species and is probably of as great phylogenetic importance as the number of chromosomes. Diploids may have one or more pairs of nucleolar chromosomes, and primary and secondary polyploids show a corresponding increase in their numbers of nucleoli countable in early telophase.

So much data on the nucleolus has accumulated that, although he gives eight pages of references, in his monograph "Nucleoli and Related Nuclear Structures"*, Prof. R. Ruggles Gates is able to quote only the more important work. Much of the earlier research obviously needs amplification or repetition using more modern technique. Gates deals briefly with the historical aspects of the subject, and then ably summarizes and critically reviews the more

* Gates, R. Ruggles, "Nucleoli and Related Nuclear Structures" Bot. Rev., 8, 337 (1942). important recent work. As well as discussing the nucleolar cycle in mitosis in the normal higher organism, he discusses and brings into line the nucleolar behaviour in some lower organisms, he tells of related structures induced by pathological conditions and also discusses nucleolar budding. He refers to variations in nucleolar size due to physiological and other causes and evaluates the work on the chemical composition of nucleoli, much of which is at present inconclusive. He examines the relationships of the nucleoli with the chromosomes, the satellites and satellite threads. Gates suggests that the nucleolus may be of genetic and developmental significance for, after being in intimate association with genic material, at metaphase a large part of it is dissolved into the cytoplasm. Finally, he stresses the phylogenetic importance of the numbers of nucleoli, asking that future reports of chromosome numbers should include a determination of the number of chremosomes with satellites or secondary constrictions and the number and sizes of the nucleoli in somatic telophase.

F. M. L. SHEFFIELd.

\section{THE HYGIENE OF THE EIGHTH ARMY IN NORTH AFRICA}

IEUT.-COLONEL H. S. GEAR, of the South 1 African Medical Corps, has described the hygiene aspects of the El Alamein victory won by the Eighth Army in North Africa (Brit. Med. J., March 18, 1944). "The Germans," says Colonel Gear, "must regret. fully realize that their neglect" of sanitation "contributed seriously" to their defeat. Some 40-50 per cent of the German and Italian front-line troops were suffering from dysentery and diarrhoa, while the Eighth Army, thanks to the efficient methods outlined by Colonel Gear, was "probably as fit mentally and physically as any army has ever been".

The supply of rations to such an army, and of purified water to the quantity, during the preparatory phases at any rate, of one gallon a day for every man, must have been tremendous problems in themselves. The battle ration was reorganized, but, when the advance began, the rapid movement and dispersal of units created serious problems of cooking and refuse disposal. Each vehicle adopted the practice of preparing its own meals, a practice which resulted in feeding out of tins, waste of rations and the scattering of food remains over large areas, with the resultant encouragement of the breeding of flies. Mobile cooking lorries were therefore instituted, which carried hot, properly cooked meals forward to fighting men. It was found that continuous training and propaganda were necessary to ensure that all units had good cooks, proper company cooking arrangements and a sense of cooking hygiene and sanitation.

The water supply is always a vitally important problem of war in what Colonel Gear modestly calls "warm climates", because so many water-borne diseases exist which can rapidly destroy the efficiency of any force. El Alamein was supplied by water pipes laid from Alexandria by British Army engineers. These carried purified water for fifty miles into the desert and to points within a few miles of the front line. This was truly a remarkable feat. But, when this supply was left behind, the captured water points, polluted by the enemy with oil, dead bodies and filth of all kinds, had to be made fit for 
use. When these in their turn were left behind, water was carried in tins and captured enemy watercontainers. Older men who experienced the chlorinated water of the War of 1914-18 will realize what lies behind the sober account of these vital matters given by Colonel Gear. They will also be interested to hear that the sun topee was abandoned without bad results. Perhaps they will remember the friends who visited their Mesopotamian messes and next day were dead from the sudden 'effects of heat'. They will be glad to hear that no cases of heat- or sunstroke or of other direct effects of heat were reported in the Western Desert. Even the tanks did not require special air-conditioning devices to protect their occupants from the effects of heat. Sun-glasses were not a general issue to the troops and Colonel Gear argues that they may actually be harmful, because people who get used to them in the relatively non-glaring atmosphere of, say, Cairo, may suffer intensely when they go to the white sand areas of the Western Desert.

It is a well-deserved tribute that Colonel Gear pays to the hygiene officers and men of the Eighth Army. Their work was not dramatic. Its daily details involved matters to which many adopt an ostrich attitude; it was hard slogging against difficulties which can only be overcome by meticulous attention to detail and insistence on discipline. Apart from the maintenance of efficient sanitation among the British forces, the Hygiene Corps had to supervise the Bedouin and other peoples who fled to El Alamein and became such a sanitary danger behind the British lines that they had to be removed. They were faced, like their predecessors at Mosul and other places on the Tigris during 1914-18, with the task of cleaning up the gigantic heaps of refuse and filth left behind by the retreating enemy. But they had the advantage of wise direction and an efficient sanitary organization.

It is time that a just tribute be paid to these men, who guarded, by their unremitting care, the lives and health of the fighters .who saved. Egypt and India. Without them the British armies might have suffered the fate of the Germans and Italians. Like the Royal Army Service Corps, the Royal Army Ordnance Corps and all the other supply services, the Hygiene Corps provided an essential part of that basis of efficiency without which the best of fighting men cannot succeed.

G. LAPAGE.

\section{FOREST PRODUCTS}

A TTENTION has been directed in NATURE from time to time to the value and possible changes in the form of utilization of timber which plywood, one of the processes of lamination, renders possible. In an address before the Royal Society of Arts entitled "Forest Products", delivered on November $22,1943, \mathrm{Mr}$. W. A. Robertson, director of the Forest Products Research Laboratory, dealt with the results of research and the future possibilities $(J$. Roy. Soc. Arts, 92, Jan. 21, 1944). Great Britain will have ta depend for its supplies of soft woods on itself (a negligible factor for some years to come), the Continen't of Europe and on Canada.

As regards the forests of the British Empire, with the exception of Canada and Newfoundland the bulk lie in the tropies or sub-tropics, starting in the west with British Honduras and Guiana, on to the Gold
Coast and Nigeria, thence through Uganda, Kenya, Tanganyika across to India, Burma and Malaya, and one large forest block in the south of Australia. The total area of these tropical forests is very large. The present area accessible to exploitation is estimated at 330,000 sq. miles, which is less than the area of softwood forests in Canada (more than 550,000 sq. miles). The two types are not comparable. Whereas the softwood coniferous forests are mostly pure (that is, of one species only) or at most two or three, in the tropical forests hardwoods prevail ; species occur of varying degrees of hardness from very soft to the hardness of iron, and thirty or more species may be mixed together in a forest. To date but a few species have been in demand in Great Britain, and only a slightly larger number by the inhabitants of the countries in which the forests exist. Difficulties of commercial extraction under such conditions can be appreciated, also the failure to develop new markets owing to the mistaken policy of past administrations in insisting that the habits of the population, whether harmful to the forests and countryside generally and to a progressive development of the people concerned, should not be interfered with.

So far as difficulties of extraction are concerned, Mr. Robertson points out that the change is coming and that the new methods of use should permit of a much larger utilization. The first stage, he points out, is the change in the introduction of lamination usually associated with the term 'plywood' though, he says, lamination means much more than this. He explains it as follows in popular terms : "By the application of lamination we give up having to rely on the properties of chunks of timber as nature has given it to us with many defects and difficulties, and by arranging the timber in layers we balance defects with clear timber, we set off the weakness of timber in one direction by its strength in another and reduce the dimensional changes, i.e., the shrinkage and swelling. Thus a beam of $6^{\prime \prime} \times 3^{\prime \prime}$ made up of $\frac{1}{2}$ inch thick laminations can be about twice as strong as the same section cut out of solid timber of the same quality and a sheet of 3-plywood is $1 \frac{1}{2}$ times as strong in shear as a board of the same thickness, while its shrinkage and expansion is only onethirteenth of the plain wood across the grain".

The possible methods of utilization thus opened out will permit of the elimination in some cases, or the distribution in others, of inevitable defects, so that they shall not occur at places of maximum stress where their weakening effect would be most felt. It may be pointed out that the application of this contention is not universal, as the oak timbers in the roof of Westminster Hall and many churches and old barns in the south of England will prove. But it is beyond dispute that with the ever-increasing demand for timber products, the new methods will permit of the use of lower quality timber "in the lightly stressed parts of an assemblage and reserve the best quality for the highly stressed regions". Finally, it permits of the utilization of short lengths of timber, the most fruitful source of waste in the past. As Robertson says, it is no secret that lamination has allowed the survival of the wooden aircraft, for without it the spars of the necessary length would have been unprocurable. Finally, it is pointed out that between 1932 and 1937 the imports of plywood into Great Britain increased from roughly 5 million cubic feet a year to 13 million, and that several of the main producing countries had reached the limits of their home-grown resources'; the importance of 